INVESTIGACIÓN

\title{
Evaluación físico-química y microbiológica de la calidad del agua de los ríos Machángara y Monjas de la red hídrica del distrito metropolitano de Quito.
}

\author{
Physic chemical and microbiological assessment of water quality in Machán- \\ gara and Monjas rivers from Quito's metropolitan district.
}

Andrea Campaña ${ }^{1}$, Ekaterina Gualoto ${ }^{1}$ y Viviana Chiluisa-Utreras ${ }^{2}$

DOI. 10.21931/RB/2017.02.02.6

\section{RESUMEN}

El presente estudio es una evaluación de la calidad y condición actual del agua de los ríos Machángara y Monjas, se midió parámetros físico-químicos como caudal, pH, temperatura, oxígeno disuelto y Potencial de Óxido Reducción (ORP) mediante monitoreo in situ, durante los meses de agosto a noviembre del 2014, y se recolectó muestras de agua para el análisis de parámetros microbiológicos (coliformes totales CT y coliformes fecales CF), aplicando el método de fermentación de tubos múltiples, establecido en el Estándar Métodos (Standard Methods) ; los análisis evidenciaron que ambos ríos superan ampliamente los límites permisibles establecidos en el Texto Unificado de Legislación Secundaria Medio Ambiental (TULSMA) para coliformes totales y fecales, temperatura y oxígeno disuelto, en el caso del río Monjas; esto impediría su aprovechamiento en actividades pecuarias, agrícolas y de preservación de flora y fauna, se evidenció además un incremento considerable en el caudal de ambos ríos y se observa que el valor de ORP de ambos ríos, es menor al valor óptimo de $650 \mathrm{mV}$; los resultados confirmaron la deficiente calidad del agua de los ríos estudiados, cuyas subcuencas forman parte de la Red Hídrica del Distrito Metropolitano de Quito (DMQ) y atraviesan zonas de gran densidad poblacional, recibiendo diariamente descargas domésticas e industriales.

Palabras Claves: Coliformes totales, coliformes fecales, calidad, parámetros fisicoquímicos, Machángara, Monjas.

\section{ABSTRACT}

This study analyses the current condition of Machángara and Monjas rivers, by evaluating the quality of its waters. Physical and chemical parameters such as: flow, $\mathrm{pH}$, temperature, dissolved oxygen and ORP were evaluated by in situ monitoring, during the months of August to November 2014. Water samples were also taken for microbiological analysis (total coliforms TC and fecal coliforms FC) in laboratory, using the Multiple Tube Fermentation method, established by the Standard Methods. The analyzes show that both rivers far exceed the permissible limits established in TULSMA for total coliforms, fecal coliforms, temperature, and dissolved oxygen in the case of Monjas River. This prevents their use for wildlife preservation, and agricultural and livestock activities. A considerable increase in the flow of both rivers was also reflected on the results; in addition, the ORP value is in both, less than the $650 \mathrm{mV}$ optimum value. The obtained results confirm the poor water quality of the studied rivers, which are an important part of the DMQ's water network and run through areas of high population density, receiving domestic and industrial discharges, daily.

Key Words: Total coliforms, fecal coliforms, water quality, physicochemical parameters, Machángara, Monjas.

\section{Introducción}

"El Distrito Metropolitano de Quito (DMQ) ocupa una superficie de $4.235,2 \mathrm{~km}^{2}$ y alberga al $15,5 \%$ de la población nacional" ${ }^{1}$.De acuerdo a las proyecciones de población dadas por el Empresa Pública Metropolitana de Agua Potable y Saneamiento, en el Plan Maestro 2010 -2040, la población del DMQ crecerá de 2,4 a 4,2 millones de habitantes en el 2040 , lo que generará que la demanda media diaria de agua potable se incremente de 7200 a $10300 \mathrm{~L} / \mathrm{s}^{2}$.

Los ríos Machángara y Monjas presentan una larga historia de contaminación, donde los efectos antropogénicos han sido determinantes, por cuanto atraviesan las zonas más pobladas de Quito y son altamente presionados por las descargas de aguas residuales, de origen industrial y doméstico ${ }^{3}$. Según datos del Plan de Desarrollo 2012-2022 emitido por la Alcaldía de Quito, los ríos Machángara y Monjas, reciben el 70\% y 20\% de las descargas de la ciudad de Quito, respectivamente, el restante $10 \%$ pertenece a descargas no registradas. (Figura 1)

De acuerdo a información emitida por la SENA$\mathrm{GUA}^{4}$, el principal foco de contaminación de estos efluentes son las descargas directas de aguas servidas y desechos provenientes de cuencas de drenaje urbano, donde los principales contaminantes que afectan a los ríos son, coliformes fecales (Escherichia coli) y totales, detergentes (tensoactivos), aceites y grasas, las cuales superan en todos los casos los límites establecidos en el TULSMA, Libro VI, Anexo I, lo que impide su aprovechamiento $^{3}$.

\footnotetext{
${ }^{1}$ Laboratorio de Investigación, Análisis y Monitoreo de Quito IAMQ, Secretaría de Ambiente, Av. Río Coca E6 - 85 e Isla Genovesa, Quito Ecuador.

${ }^{2}$ Laboratorios de Ciencias de la Vida CIVABI, Universidad Politécnica Salesiana, Quito - Ecuador.
} 

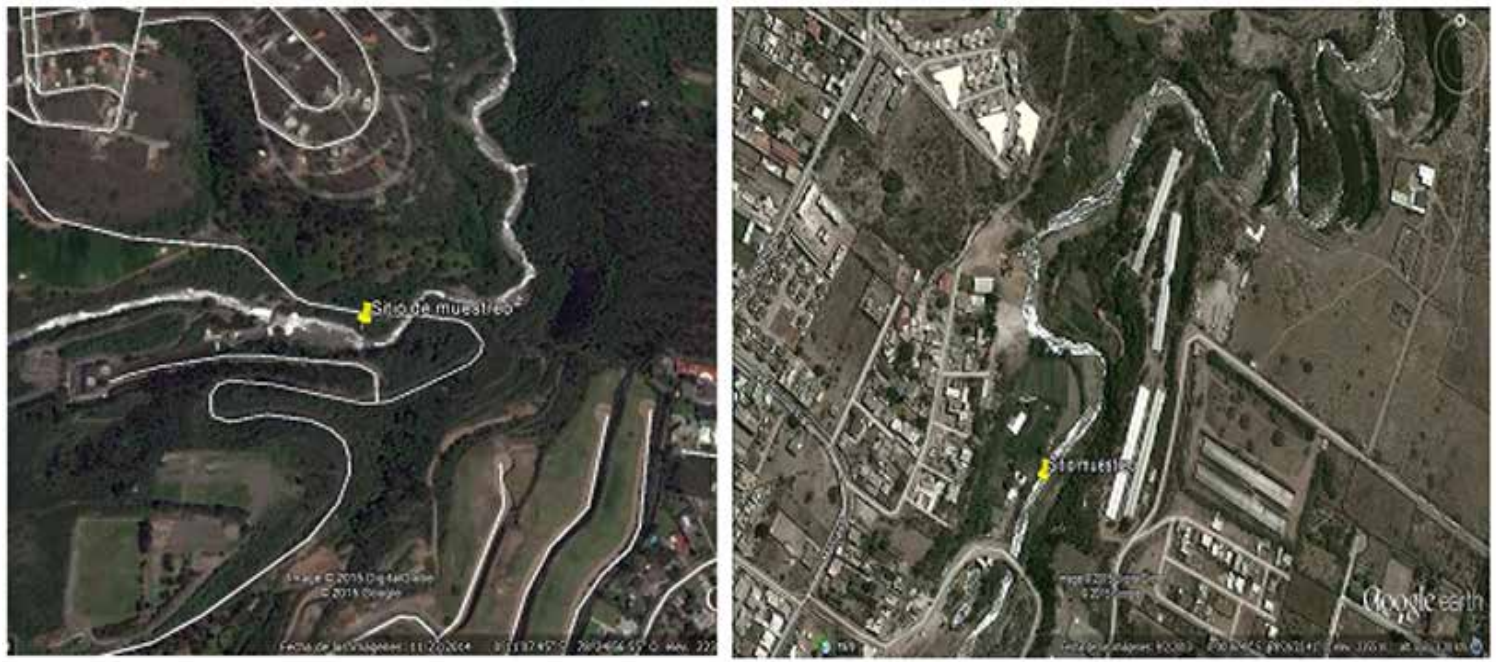

Figura 1: Ubicación geográfica de los puntos de muestreo de los Ros Machángara y Monjas

\section{Introducción}

"El Distrito Metropolitano de Quito (DMQ) ocupa una superficie de $4.235,2 \mathrm{~km}^{2}$ y alberga al $15,5 \%$ de la población nacional"1.De acuerdo a las proyecciones de población dadas por el Empresa Pública Metropolitana de Agua Potable y Saneamiento, en el Plan Maestro 2010 -2040, la población del DMQ crecerá de 2,4 a 4,2 millones de habitantes en el 2040, lo que generará que la demanda media diaria de agua potable se incremente de 7200 a $10300 \mathrm{~L} / \mathrm{s}^{2}$.

Los ríos Machángara y Monjas presentan una larga historia de contaminación, donde los efectos antropogénicos han sido determinantes, por cuanto atraviesan las zonas más pobladas de Quito y son altamente presionados por las descargas de aguas residuales, de origen industrial y doméstico ${ }^{3}$. Según datos del Plan de Desarrollo 2012-2022 emitido por la Alcaldía de Quito, los ríos Machángara y Monjas, reciben el 70\% y 20\% de las descargas de la ciudad de Quito, respectivamente, el restante $10 \%$ pertenece a descargas no registradas. (Figura 1)

De acuerdo a información emitida por la SENAGUA ${ }^{4}$, el principal foco de contaminación de estos efluentes son las descargas directas de aguas servidas y desechos provenientes de cuencas de drenaje urbano, donde los principales contaminantes que afectan a los ríos son, coliformes fecales (Escherichia coli) y totales, detergentes (tensoactivos), aceites y grasas, las cuales superan en todos los casos los límites establecidos en el TULSMA, Libro VI, Anexo I, lo que impide su aprovechamiento ${ }^{3}$.

Villacís ${ }^{5}$, indica que algunos de los factores que agravan los problemas de contaminación en los ríos del DMQ son: la elevada densidad poblacional del cantón Quito, que genera una mayor presión de emisiones de desechos y demanda de agua; el poco control existente en los sitios de acopio de desechos sólidos, lo que facilita que las industrias contaminen ríos y fuentes de agua cercanas; que el DMQ no cuenta con un sistema de alcantarillado que separe las aguas residuales contaminadas de las aguas de lluvia y por último, no existe tratamiento post-uso del agua potable, y esta es vertida sin tratamiento alguno a los ríos ${ }^{6}$.

Los agentes patógenos ligados a la transmisión hídrica de enfermedades son las bacterias, virus, protozoos, helmintos y cianobacterias. Estos microorganismos pueden causar enfermedades con diferentes niveles de gravedad, desde una gastroenteritis simple hasta cuadros graves de diarrea, disentería, hepatitis o fiebre tifoide ${ }^{7}$. Los Indicadores Básicos de Salud del 2010, reportan 32676 casos de diarreas y gastroenteritis de origen infeccioso, y ubican estas patologías en el segundo lugar de las enfermedades de notificación obligatoria ${ }^{8}$.
En consideración a la información referida, la presente investigación evidenció el estado de contaminación actual de los ríos Machángara y Monjas a través de la determinación de parámetros físico-químicos y microbiológicos (coliformes totales y fecales) $)^{9}$ en dos puntos de la red hídrica del DMQ, para orientar la investigación científica hacia la generación de propuestas técnicas basada en acciones comunitarias, medidas administrativas y operaciones técnicas viables; que busquen solucionar los problemas de contaminación severa que sufren los dos principales ríos capitalinos.

\section{MATERIALES Y METODOS}

\section{Localización}

Los sitios de muestreo seleccionados tanto para el río Machángara, como para el río Monjas, se escogieron considerando factores de seguridad y accesibilidad y corresponden a los puntos establecidos por la Secretaría de Ambiente para el monitoreo de la calidad del agua en la Red Hídrica del DMQ, su ubicación geográfica, coordenadas y altitud se muestra en la Tabla 1 éstos datos fueron registrados con el uso de un GPS Garmin GPSMAP 62sc. Se estudió 3 muestras de agua por cada río y en cada muestra se midió los parámetros físico-químicos: $\mathrm{pH}$, temperatura, ORP, oxígeno disuelto, caudal; y los parámetros microbiológicos: coli-

$$
\frac{\text { Valor de NMP }(\text { de la tabla }) \times 10}{\text { Mayor volumen estudiado }}=m
$$

formes totales, coliformes fecales.

\section{Medición de parámetros in situ}

Para determinar $\mathrm{pH}$, temperatura y ORP se usó un equipo multiparámetros marca Consort, modelo C562, y con un Kit Multiparámetros, marca Hach, modelo HQ40d, se midió el oxígeno disuelto. Para la medición in situ del caudal se utilizó un molinete Global Water 800-876-1172, modelo FP111, serie 1124158994.

\section{Determinación de coliformes totales y fecales}

La determinación de coliformes totales y fecales se realizó aplicando la Técnica de Fermentación de Tubos Múltiples, en conformidad a lo establecido en el Standard Methods 9222 A-E. Por tratarse de agua muy contaminada y con el fin de obtener resultados más precisos, se realizaron diluciones en escala logarítmica hasta $10^{-6}$ formando un juego de cinco tubos, del que derivó 


\begin{tabular}{|l|l|c|c|}
\multicolumn{1}{c|}{ LUGAR } & \multicolumn{1}{|c}{ UBICACIÓN } & $\begin{array}{c}\text { COORDENADAS } \\
\text { GEOGRÁFICAS }\end{array}$ & $\begin{array}{c}\text { ALTITUD } \\
\text { (mts) }\end{array}$ \\
\hline $\begin{array}{l}\text { Orilla río } \\
\text { Machángara }\end{array}$ & $\begin{array}{l}\text { Provincia de Pichincha, Cantón Quito - } \\
\text { Parroquia Cumbayá- Central } \\
\text { Hidroeléctrica Cumbayá EEQ }\end{array}$ & $78^{\circ} 24^{\prime} 56.55^{\prime \prime}$ & 2231 \\
\hline $\begin{array}{l}\text { Orilla río } \\
\text { Monjas }\end{array}$ & $\begin{array}{l}\text { Provincia de Pichincha- Cantón Quito - } \\
\text { Parroquia San Antonio- Piscinas } \\
\text { Municipales }\end{array}$ & $78^{\circ} 26^{\prime} 22.41^{\prime \prime}$, & 2342 \\
\hline
\end{tabular}

Tabla 1: Ubicación puntos de muestreo

\begin{tabular}{|c|c|c|c|c|}
\hline \multicolumn{3}{|c|}{ Parámetros físico-químicosnormados } & Machángara & Monjas \\
\hline \multirow[t]{3}{*}{$\mathrm{pH}$} & $\begin{array}{c}\text { Preservación flora } \\
\text { y fauna }\end{array}$ & $6,5-9$ & \multirow[t]{3}{*}{7,39} & \multirow[t]{3}{*}{7,03} \\
\hline & Uso agricola & $6-9$ & & \\
\hline & Uso pecuario & $6-9$ & & \\
\hline \multirow[t]{2}{*}{$\begin{array}{l}\text { Oxigeno } \\
\text { disuelto }\end{array}$} & $\begin{array}{c}\text { Preservación flora } \\
\text { y fauna }\end{array}$ & $\begin{array}{c}\text { No menor a } \\
6 \mathrm{mg} / 1\end{array}$ & \multirow[t]{2}{*}{7,01} & \multirow[t]{2}{*}{5,5} \\
\hline & Uso pecuario & $3,06 \mathrm{mg} / 1$ & & \\
\hline Temperatura & $\begin{array}{c}\text { Preservación flora } \\
\text { y fauna }\end{array}$ & $\begin{array}{l}\text { Condiciones } \\
\text { naturales }+3\end{array}$ & 21,5 & 22,5 \\
\hline Caudal & - & - & 1,8 & 0,8 \\
\hline ORP & - & - & 268,3 & 313,3 \\
\hline
\end{tabular}

Tabla 2: Comparación de valores medios de parámetros físico-químicos con límites permisibles de TULSMA

el código de 3 dígitos para el Número más probable (NMP). Estas diluciones se sembraron siguiendo el procedimiento establecido por el método ${ }^{10}$.

\section{Tratamiento de los resultados}

El procesamiento de datos obtenidos se realizó de acuerdo a la matriz desarrollada y adaptada por las autoras. Una vez determinada la combinación más adecuada de diluciones se realizó el cálculo del NMP de coliformes totales y fecales, en función de la tabla de lectura y registro del NMP establecida en el Standard Methods. El valor final se calculó aplicando la siguiente fórmula:

Se realizó un análisis de correlación estadística entre los datos obtenidos de la medición de parámetros físico-químicos, para determinar el grado de dependencia existente entre ellos.

\section{RESULTADOS Y DISCUSIÓN}

\section{Parámetros físico-químicos}

Los muestreos se realizaron en los meses de agosto, septiembre y octubre del 2014 en intervalos de 15 días, obteniéndose los valores de $\mathrm{pH}$ que se muestran en la Tabla 2, los cuales son comparados con los límites permisibles para aguas de uso agrícola, pecuario y preservación de flora y fauna, establecidos por la normativa TULSMA, Libro VI, Anexo 1, que rige al DMQ ${ }^{11}$. Estos valores muestran que los procesos de degradación (autodepuración), son mínimos; ya que normalmente bajo procesos activos de degradación biológica el $\mathrm{pH}$ natural tiende a acidificarse.

Esta aseveración se sustenta con base en los valores de Demanda biológica de oxígeno (DBO5) reportados por la Secretaría de Ambiente en el año 2013, que muestran concentraciones de 107,8 ppm para el río Machángara y de 98,00 ppm, para el río Monjas, poniendo en evidencia que no se está produciendo una biodegradación apreciable.

El valor medio de oxígeno disuelto del río Machángara $(7,01$ $\mathrm{mg} / \mathrm{L}$ ) es superior al límite mínimo permisible establecido por el TULSMA para aguas de uso pecuario y preservación de flora y fauna, es decir presenta un valor mayor a $6 \mathrm{mg} / \mathrm{L}$, por otro lado el río Monjas mostró una concentración media de oxígeno disuelto (5,50 mg/L), menor al límite mínimo permisible establecido para preservación de flora y fauna, pero dentro del límite establecido para aguas de uso pecuario.

Puesto que el oxígeno disuelto está directamente relacionado con el potencial Redox, a medida que el ORP disminuye por la presencia de altas densidades microbianas, disminuye la concentración de oxígeno disuelto, lo que provoca la reducción de iones y moléculas importantes para la nutrición de microorganismos y formas de vida superior ${ }^{12}$.

Reinoso ${ }^{13}$, determina un caudal mensual promedio para el río Monjas de $0.03548 \mathrm{~m}^{3} / \mathrm{s}$ y de $0.4165 \mathrm{~m}^{3} / \mathrm{s}$ para el río Machángara en el año 2013, en tanto que los datos obtenidos por la investigación, mostrados en la Tabla 2, evidencian un incremento considerable del caudal en ambos ríos. Esto puede deberse al constante crecimiento poblacional que sufren las zonas de estudio y por tanto al aumento de las descargas domésticas e industriales. Los factores ambientales como la temperatura y principalmente las precipitaciones, también influyen en este aumento, por ende, existe un mayor flujo de descargas al sistema de alcantarillado, elevando el caudal diario de estos ríos ${ }^{14,15}$.

Los valores medios de ORP obtenidos para los ríos Monjas 


\begin{tabular}{|c|c|c|c|c|c|}
\hline $\begin{array}{l}\text { Río } \\
\text { Machángara }\end{array}$ & Temperatura & $\begin{array}{l}\text { Oxigeno } \\
\text { disuelto }\end{array}$ & $p H$ & $O R P$ & Caudal \\
\hline Temperatura & 1 & & & & \\
\hline $\begin{array}{l}\text { Oxigeno } \\
\text { disuelto }\end{array}$ & $-0,8538366$ & 1 & & & \\
\hline$p H$ & 0,09578263 & 0,43636511 & 1 & & \\
\hline ORP & 0,82311266 & $\begin{array}{c}- \\
0,99840762\end{array}$ & $-0,48642727$ & 1 & \\
\hline Caudal & $-0,81415234$ & 0,99740596 & 0,5 & $-0,99987828$ & 1 \\
\hline Río Monjas & Temperatura & $\begin{array}{l}\text { Oxigeno } \\
\text { disuelto }\end{array}$ & $p H$ & ORP & Caudal \\
\hline Temperatura & 1 & & & & \\
\hline $\begin{array}{l}\text { Oxigeno } \\
\text { disuelto }\end{array}$ & $-0,52828401$ & 1 & & & \\
\hline$p H$ & 0,58065133 & $\begin{array}{c}- \\
0,99801929\end{array}$ & 1 & & \\
\hline$O R P$ & $-0,99980188$ & 0,51127892 & $-0,56433084$ & 1 & \\
\hline Caudal & 1 & $\begin{array}{c}- \\
0,52828401\end{array}$ & 0,58065133 & $-0,99980188$ & 1 \\
\hline
\end{tabular}

Tabla 3: Correlación parámetros físico-químicos ríos Machángara y Monjas

\section{Introducción}

"El Distrito Metropolitano de Quito (DMQ) ocupa una superficie de $4.235,2 \mathrm{~km}^{2}$ y alberga al $15,5 \%$ de la población nacional"1. De acuerdo a las proyecciones de población dadas por el Empresa Pública Metropolitana de Agua Potable y Saneamiento, en el Plan Maestro 2010 -2040, la población del DMQ crecerá de 2,4 a 4,2 millones de habitantes en el 2040, lo que generará que la demanda media diaria de agua potable se incremente de 7200 a $10300 \mathrm{~L} / \mathrm{s}^{2}$.

Los ríos Machángara y Monjas presentan una larga historia de contaminación, donde los efectos antropogénicos han sido determinantes, por cuanto atraviesan las zonas más pobladas de Quito y son altamente presionados por las descargas de aguas residuales, de origen industrial y doméstico ${ }^{3}$. Según datos del Plan de Desarrollo 2012-2022 emitido por la Alcaldía de Quito, los ríos Machángara y Monjas, reciben el 70\% y 20\% de las descargas de la ciudad de Quito, respectivamente, el restante $10 \%$ pertenece a descargas no registradas. (Figura 1)

De acuerdo a información emitida por la SENAGUA ${ }^{4}$, el principal foco de contaminación de estos efluentes son las descargas directas de aguas servidas y desechos provenientes de cuencas de drenaje urbano, donde los principales contaminantes que afectan a los ríos son, coliformes fecales (Escherichia coli) y totales, detergentes (tensoactivos), aceites y grasas, las cuales superan en todos los casos los límites establecidos en el TULSMA, Libro VI, Anexo I, lo que impide su aprovechamiento ${ }^{3}$.

Villacís ${ }^{5}$, indica que algunos de los factores que agravan los problemas de contaminación en los ríos del DMQ son: la elevada densidad poblacional del cantón Quito, que genera una mayor presión de emisiones de desechos y demanda de agua; el poco control existente en los sitios de acopio de desechos sólidos, lo que facilita que las industrias contaminen ríos y fuentes de agua cercanas; que el DMQ no cuenta con un sistema de alcantarillado que separe las aguas residuales contaminadas de las aguas de llu-

\begin{tabular}{|l|c|c|c|c|c|c|}
\hline $\begin{array}{c}\text { Criterio } \\
\text { TULSMA } \\
\text { Libro VI }\end{array}$ & \multicolumn{2}{|c|}{$\begin{array}{c}\text { Limite } \\
\text { permisible }\end{array}$} & \multicolumn{2}{|c|}{ Machángara } & \multicolumn{2}{|c|}{ Monjas } \\
\cline { 2 - 7 } & $\mathrm{CT}$ & $\mathrm{CF}$ & $\mathrm{CT}$ & $\mathrm{CF}$ & $\mathrm{CT}$ & $\mathrm{CF}$ \\
\hline $\begin{array}{l}\text { Preservación } \\
\text { flora y fauna }\end{array}$ & - & 200 & & & & \\
\hline Uso agricola & 1000 & - & 337777 & 181110 & 407777 & 234444 \\
\hline $\begin{array}{l}\text { Uso } \\
\text { pecuario }\end{array}$ & $\begin{array}{c}\text { Menor } \\
\text { a }\end{array}$ & $\begin{array}{c}\text { Promedio } \\
\text { mensual } \\
\text { menor a } \\
5000\end{array}$ & NMP/100ml & NMP/100ml & NMP/100ml & NMP/100ml \\
\hline
\end{tabular}

Tabla 4: Comparación de valores medios de NMP/100ml para coliformes totales (CT) y coliformes fecales (CF) con límites permisibles del TULSMA 
via y por último, no existe tratamiento post-uso del agua potable, y esta es vertida sin tratamiento alguno a los ríos ${ }^{6}$.

Los agentes patógenos ligados a la transmisión hídrica de enfermedades son las bacterias, virus, protozoos, helmintos y cianobacterias. Estos microorganismos pueden causar enfermedades con diferentes niveles de gravedad, desde una gastroenteritis simple hasta cuadros graves de diarrea, disentería, hepatitis o fiebre tifoide ${ }^{7}$. Los Indicadores Básicos de Salud del 2010, reportan 32676 casos de diarreas y gastroenteritis de origen infeccioso, y ubican estas patologías en el segundo lugar de las enfermedades de notificación obligatoria ${ }^{8}$.

En consideración a la información referida, la presente investigación evidenció el estado de contaminación actual de los ríos Machángara y Monjas a través de la determinación de parámetros físico-químicos y microbiológicos (coliformes totales y fecales) $)^{9}$ en dos puntos de la red hídrica del DMQ, para orientar la investigación científica hacia la generación de propuestas técnicas basada en acciones comunitarias, medidas administrativas y operaciones técnicas viables; que busquen solucionar los problemas de contaminación severa que sufren los dos principales ríos capitalinos.

\section{MATERIALES Y METODOS}

\section{Localización}

Los sitios de muestreo seleccionados tanto para el río Machángara, como para el río Monjas, se escogieron considerando factores de seguridad y accesibilidad y corresponden a los puntos establecidos por la Secretaría de Ambiente para el monitoreo de la calidad del agua en la Red Hídrica del DMQ, su ubicación geográfica, coordenadas y altitud se muestra en la Tabla 1 éstos datos fueron registrados con el uso de un GPS Garmin GPSMAP 62sc. Se estudió 3 muestras de agua por cada río y en cada muestra se midió los parámetros físico-químicos: $\mathrm{pH}$, temperatura, ORP, oxígeno disuelto, caudal; y los parámetros microbiológicos: coliformes totales, coliformes fecales.

\section{Medición de parámetros in situ}

Para determinar $\mathrm{pH}$, temperatura y ORP se usó un equipo multiparámetros marca Consort, modelo C562, y con un Kit Multiparámetros, marca Hach, modelo HQ40d, se midió el oxígeno disuelto. Para la medición in situ del caudal se utilizó un molinete Global Water 800-876-1172, modelo FP111, serie 1124158994.

\section{Determinación de coliformes totales y fecales}

La determinación de coliformes totales y fecales se realizó aplicando la Técnica de Fermentación de Tubos Múltiples, en conformidad a lo establecido en el Standard Methods 9222 A-E. Por tratarse de agua muy contaminada y con el fin de obtener resultados más precisos, se realizaron diluciones en escala logarítmica hasta $10^{-6}$ formando un juego de cinco tubos, del que derivó el código de 3 dígitos para el Número más probable (NMP). Estas diluciones se sembraron siguiendo el procedimiento establecido por el método ${ }^{10}$.

\section{Tratamiento de los resultados}

El procesamiento de datos obtenidos se realizó de acuerdo a la matriz desarrollada y adaptada por las autoras. Una vez determinada la combinación más adecuada de diluciones se realizó el cálculo del NMP de coliformes totales y fecales, en función de la tabla de lectura y registro del NMP establecida en el Standard Methods. El valor final se calculó aplicando la siguiente fórmula:

Se realizó un análisis de correlación estadística entre los datos obtenidos de la medición de parámetros físico-químicos, para determinar el grado de dependencia existente entre ellos.

\section{RESULTADOS Y DISCUSIÓN}

\section{Parámetros físico-químicos}

Los muestreos se realizaron en los meses de agosto, septiembre y octubre del 2014 en intervalos de 15 días, obteniéndose los valores de $\mathrm{pH}$ que se muestran en la Tabla 2, los cuales son comparados con los límites permisibles para aguas de uso agrícola, pecuario y preservación de flora y fauna, establecidos por la normativa TULSMA, Libro VI, Anexo 1, que rige al DMQ ${ }^{11}$. Estos valores muestran que los procesos de degradación (autodepuración), son mínimos; ya que normalmente bajo procesos activos de degradación biológica el $\mathrm{pH}$ natural tiende a acidificarse.

Esta aseveración se sustenta con base en los valores de Demanda biológica de oxígeno (DBO5) reportados por la Secretaría de Ambiente en el año 2013, que muestran concentraciones de 107,8 ppm para el río Machángara y de 98,00 ppm, para el río Monjas, poniendo en evidencia que no se está produciendo una biodegradación apreciable.

El valor medio de oxígeno disuelto del río Machángara (7,01 $\mathrm{mg} / \mathrm{L}$ ) es superior al límite mínimo permisible establecido por el TULSMA para aguas de uso pecuario y preservación de flora y fauna, es decir presenta un valor mayor a $6 \mathrm{mg} / \mathrm{L}$, por otro lado el río Monjas mostró una concentración media de oxígeno disuelto (5,50 mg/L), menor al límite mínimo permisible establecido para preservación de flora y fauna, pero dentro del límite establecido para aguas de uso pecuario.

Puesto que el oxígeno disuelto está directamente relacionado con el potencial Redox, a medida que el ORP disminuye por la presencia de altas densidades microbianas, disminuye la concentración de oxígeno disuelto, lo que provoca la reducción de iones y moléculas importantes para la nutrición de microorganismos y formas de vida superior ${ }^{12}$.

Reinoso $^{13}$, determina un caudal mensual promedio para el río Monjas de $0.03548 \mathrm{~m}^{3} / \mathrm{s}$ y de $0.4165 \mathrm{~m}^{3} / \mathrm{s}$ para el río Machángara en el año 2013, en tanto que los datos obtenidos por la investigación, mostrados en la Tabla 2, evidencian un incremento considerable del caudal en ambos ríos. Esto puede deberse al constante crecimiento poblacional que sufren las zonas de estudio y por tanto al aumento de las descargas domésticas e industriales. Los factores ambientales como la temperatura y principalmente las precipitaciones, también influyen en este aumento, por ende, existe un mayor flujo de descargas al sistema de alcantarillado, elevando el caudal diario de estos ríos ${ }^{14,15}$.

Los valores medios de ORP obtenidos para los ríos Monjas $(268,3 \mathrm{mV})$ y Machángara $(313,3 \mathrm{mV})$ son inferiores a $650 \mathrm{mV}$, que es el valor de referencia para que el agua sea considerada segura. De acuerdo a Lynch y Poole (1979) citados por Fuentes ${ }^{12}$, esto es indicativo de un ambiente altamente reductor, que puede ser ocasionado por las descargas masivas de materia orgánica oxidable del alcantarillado sanitario, lo que aumenta la densidad de bacterias anaerobias facultativas, como las bacterias del grupo Coliformes, quienes se encuentran en grandes cantidades en los ríos estudiados, tal como se muestra en los resultados obtenidos del análisis microbiológico y cuya actividad metabólica altera el potencial Redox.

\section{Análisis de Correlación}

El análisis de correlación nos permitió medir el grado de relación existente entre los parámetros estudiados. En la Tabla 3 se muestran los valores obtenidos para los parámetros agrupados de ambos ríos. De los cinco parámetros medidos en cada río, tres de ellos (temperatura, oxígeno disuelto y $\mathrm{pH}$ ), se contemplan en la normativa vigente. Para el río Machángara, uno de los tres parámetros normados (temperatura), no se encuentran dentro de los límites permisibles establecidos y que dos de los cinco parámetros monitoreados evidencian valores fuera de los límites determinados para aguas de calidad. Por otro lado, en el río Monjas, que dos 
de los tres parámetros normados (oxígeno disuelto, temperatura) se ubican fuera de norma y cuatro de los cinco parámetros analizados muestran baja calidad.

Se observa que existe una correlación negativa considerable, entre la temperatura y el ORP con el oxígeno disuelto. También se evidencia una correlación negativa considerable entre el caudal y ORP, a diferencia de la correlación positiva que presentan el caudal y el oxígeno disuelto. Existe una correlación negativa considerable, entre el pH y el oxígeno disuelto. Además, existe una correlación negativa considerable entre el ORP, con el caudal y la temperatura, a diferencia de la correlación positiva perfecta que presentan el caudal y la temperatura. Esto indica que la variación en alguno de los parámetros, siempre incidirá de forma positiva o negativa sobre los demás, lo que puede afectar la calidad del agua.

\section{Parámetros Microbiológicos}

De los valores de NMP obtenidos de las tres repeticiones realizadas con cada muestra de los ríos Machángara y Monjas, así como del valor medio calculado con estos datos, se obtuvo los valores medios y un valor medio total para Coliformes Totales y Fecales de ambos ríos, como se muestra en la Tabla 4. Los resultados evidencian que el río Machángara supera los límites establecidos por la normativa vigente, puesto que presenta una concentración media de CF de 181110 $\mathrm{NMP} / 100 \mathrm{ml}$ que es 905,5 veces superior al límite máximo permisible establecido para preservación de flora y fauna, y 36,22 veces superior al promedio mensual de 5000 establecido para aguas de uso pecuario. En tanto que la concentración media de Coliformes Totales (CT) para uso agrícola y pecuario es 337,7 veces superior a la norma, presentando un valor de $337777 \mathrm{NMP} / 100 \mathrm{ml}$.

El río Monjas tampoco cumple con lo establecido por la norma puesto que la concentración de CF, es 1172,22 veces superior al límite permisible establecido para la conservación de flora y fauna y 46,88 veces superior al promedio mensual establecido para uso agrícola, presentando un valor de $234444 \mathrm{NMP} / 100 \mathrm{ml}$. En tanto que la concentración media de CT para uso agrícola y pecuario es 234,4 veces superior a norma.

Según Reinoso ${ }^{13}$, la concentración de Coliformes Totales en el río Machángara es de 24 millones NMP/100ml y la de CF $24000 \mathrm{NM}$ $\mathrm{P} / 100 \mathrm{ml}$ y según el documento "Perspectivas del ambiente y cambio climático en el medio urbano del DMQ" del Fondo Ambiental DMQ (2011), el río Machángara presenta 6,60×107 NMP/100ml de CT y $5,61 \times 10^{7} \mathrm{NMP} / 100 \mathrm{ml}$ de CF y el río Monjas CT $3,53 \times 10^{7} \mathrm{NM}-$ $\mathrm{P} / 100 \mathrm{ml}$ de CT y $1,10 \times 10^{6} \mathrm{NMP} / 100 \mathrm{ml}$ de CF. Estos valores difieren con los obtenidos en la investigación, pero esta variación es aparente, puesto que el método está basado en el principio de incertidumbre que ofrece un límite de confianza sumamente amplio. Este grado de incertidumbre no da certezas, pero nos permite obtener un valor estimado ${ }^{10}$.

\section{CONCLUSIONES Y RECOMENDACIONES}

El río Monjas presenta mayor deterioro de la calidad microbiológica del agua, pues sus valores de NMP para CT y principalmente CF son levemente mayores a los registrados en el río Machángara, esto puede deberse a que en el sitio de muestreo del río Monjas se encuentra un punto directo de descarga de aguas residuales domésticas e industriales, por ello los residuos sanitarios no logran someterse a los procesos de autodepuración propios del río, además, la elevada temperatura registrada conjuntamente con los bajos valores bajos de ORP y de caudal presentados en este punto, generan condiciones que permiten una mayor supervivencia y proliferación de los microorganismos. En el río Machángara los procesos propios del funcionamiento de la hidroeléctrica de Cumbayá (tamizado, agitación y decantación), permiten reducir la cantidad de materia orgánica presente en las aguas y reducir levemente los valores de NMP en sus aguas.
Existen ciertos inconvenientes que impiden el cumplimiento cabal de la norma con respecto a parámetros microbiológicos, uno de ellos es la normativa vigente (TULSMA), donde se establece como parámetro para determinar la calidad microbiología del agua el Número Más Probable (NMP) hecho que limita la selección de metodologías a ser aplicadas en la evaluación microbiológica. Uno de los pocos métodos que permiten su estimación es la Técnica de Fermentación de Tubos Múltiples mismo que no se adapta a la realidad ambiental de nuestro entorno, volviéndose necesaria la introducción de modificaciones o el empleo de distintos métodos de cuantificación, acordes a los altos grados de contaminación que presentan nuestros ríos, por ello, sería importante considerar una posible modificación de la normativa, para que se establezca los límites permisibles de coliformes fecales y totales en términos de UFC y no en NMP. Esta modificación permitirá el uso de métodos de evaluación más rápidos, sencillos y confiables.l

\section{Agradecimientos}

Al Dr. Miguel Gualoto y al Dr. Luis Valdés por su valioso apoyo y guía. A la Secretaría de Ambiente del Distrito Metropolitano de Quito y al Instituto Nacional de Energías Renovables por su amable colaboración.

\section{Referencias bibliográficas}

1. Municipio del DMQ. (diciembre de 2011). Plan de Desarrollo 2012-2022. Recuperado el 07 de abril de 2015, de Google: http://www.centrocultural-quito.com/imagesFTP/13644.Plan_de_Desarrollo_Local_2012_2022. pdf

2. EPMAPS. (marzo de 2011). Google. Recuperado el 04 de abril de 2015, de Plan Maestro de Agua Potable 2010-2040: http://www.aguaquito.gob. ec/sites/default/files/documentos/plan_maestro_agua_potable.pdf

3. Fondo Ambiental DMQ. (2011). "Perspectivas del ambiente y cambio climático en el medio urbano” ECCO-Distrito Metropolitano de Quito. Quito, Pichincha, Ecuador: CrearImagen.

4. SENAGUA. (febrero de 2009). "Problemática y Conflictos sobre los Recursos Hídricos por efectos del cambio Climático". Recuperado el 28 de febrero de 2015, de Google: http://www.utpl.edu.ec/obsa/wp-content/ uploads/2012/09/3_ded-senagua_capt-0_resumen-ejecutivo.pdf

5. Villacís, B. (2005). La Crisis del Oro Azul: Un análisis de la sustentabilidad del agua en la ciudad de Quito. Recuperado el 2015 de abril de 08, de Repositorio FLACSO: http://repositorio.flacsoandes.edu.ec/bitstream/10469/269/3/TFLACSO-02-2005BAV.pdf

6. Juez, O. (04 de septiembre de 2011). Mar y ríos, depósitos de aguas servidas. (Diario La Hora, Entrevistador)

7. Arcos, M. (2005). Indicadores microbiológicos de contaminación de las fuentes de agua. Nova-Publicación Científica, 70-73.

8. Ministerio de Salud Pública. (2010). Indicadores Básicos de Salud Ecuador 2010. Recuperado el 08 de abril de 2015, de Google: file://C:/Users/ User/Downloads/sds_Indicadores\%202010\%20ULTIMO.pdf

9. Palacios, C. (2013). Distribución de coliformes fecales en el área marina de la costa ecuatoriana en las provincias de Esmeraldas y Manabí, 2008-2013. Recuperado el 08 de abril de 2015, de Google: http://www. inocar.mil.ec/web/phocadownloadpap/actas_oceanograficas/acta18/ OCE1801_6.pdf

10. Rice, E. (2012). Standard Methods. Washington: America Public Health Association

11. TULSMA. (31 de marzo de 2003). Google. Recuperado el 20 de febrero de 2015, de Norma de Calidad Ambiental y Descargas de Efluentes: Recurso Agua: http://faolex.fao.org/docs/pdf/ecu112180.pdf

12. Fuentes, F. (2002). Google. Recuperado el 2015 de junio de 22, de Manual de Laboratorios: Ecología de Microorganismos: http://ocw.um.es/ciencias/ecologia/lectura-obligatoria-1/p1-intro.pdf

13. Reinoso, I. (2015). Evaluación del Río Machámgara. Quito: Universidad Politécnica Nacional.

14. Granda, O. (2007). Plan Parcial de Ordenamiento Territorial de las Parroquias Equinoccionales (Calacalí, Pomasqui y San Antonio de Pichincha). Consultoria, EMAAPQ, Quito.

15. Gobierno de Pichincha. (2012). Plan de Desarrollo y Ordenamiento Territorial de la Parroquia de San Antonio de Pichincha 2012-2015. Gobierno Autónomo Desentralizado de Parroquial de San Antonio de Pichincha. Quito: Consejo de Planificación Provincial. 